\title{
Isoliquiritigenin-Induced Differentiation in Mouse Melanoma B16F0 Cell Line
}

\author{
Xiaoyu Chen, ${ }^{1}$ Bo Zhang, ${ }^{1}$ Xuan Yuan, ${ }^{1,2}$ Fan Yang, ${ }^{1}$ Jinglei Liu, ${ }^{1}$ Hong Zhao, ${ }^{1}$ \\ Liangliang Liu, ${ }^{1}$ Yanming Wang, ${ }^{1}$ Zhenhua Wang, ${ }^{3}$ and Qiusheng Zheng ${ }^{1,3}$ \\ ${ }^{1}$ Key Laboratory of Xinjiang Endemic Phytomedicine Resources of Ministry of Education, School of Pharmacy, \\ Shihezi University, Shihezi 832002, China \\ ${ }^{2}$ Lanzhou University Second Hospital, Lanzhou University, Lanzhou 730000, China \\ ${ }^{3}$ Life Science School, Yantai University, Yantai 264000, China \\ Correspondence should be addressed to Qiusheng Zheng, johnsonjem@hotmail.com
}

Received 5 September 2012; Revised 3 November 2012; Accepted 8 November 2012

Academic Editor: Jing Yi

Copyright ( 12012 Xiaoyu Chen et al. This is an open access article distributed under the Creative Commons Attribution License, which permits unrestricted use, distribution, and reproduction in any medium, provided the original work is properly cited.

The chemotherapeutical treatment is very limited for malignant melanoma, a highly lethal disease occurs globally. Natural products derived from traditional Chinese medicine licorice are attractive in quest new treatments due to their anti-tumor activities. A new dietary flavonoid isoliquiritigenin (ISL) were thus investigated to indentify its anti-melanoma activities on mouse melanoma B16F0 cells in present study. Using biochemical and free radical biological experiments in vitro, we identified the prodifferentiated profiles of ISL and evaluated the role of reactive oxygen species (ROS) during B16F0 cell differentiation. The data showed a strong dose-response relationship between ISL exposure and the characteristics of B16F0 differentiation in terms of morphology changes and melanogenesis. The accumulated intercellular ROS during exposure are necessary to support ISL-induced differentiation, which was proven by additional redox modulators. It was confirmed further by the relative activities of enzymes and genes modulated melanogenesis in ISL-treatments with or without ROS modulators. The tumorigenicity of ISL-treated cells was limited significantly by using the colony formation assay in vitro and an animal model assay in vivo respectively. Our research demonstrated that isoliquiritigenin is a differentiation-inducing agent, and its mechanisms involve ROS accumulation facilitating melanogenesis.

\section{Introduction}

Melanoma is the most aggressive form of skin cancer [1]. The mouse melanoma cell line, B16, which is isolated from C57BL/6 mice, is often used as a cellular differentiation model. The upregulation of melanin biosynthesis and induction of dendrite outgrowths are the typical differentiation characteristics in melanoma cells. Some studies demonstrated the differentiation of B16 cells into mature melanocyte-like cells by induction through $\alpha$-melanocytestimulating hormone [2], signal transduction pathway inhibitors [3, 4], mannosylerythritol lipid [5], and retinoic acid treatments [6]. The differentiation of melanoma cells into a terminal differentiation stage will be an effective strategy in preventing death caused by melanoma.
Reactive oxygen species (ROS) play a crucial role in cellular differentiation [7]. ROS are toxic to cells at high concentrations but act as intracellular second messengers at sublethal concentrations, leading to the transcriptional activation of various genes, including cell proliferation and differentiation. The (reduction-oxidation) redox status also plays an important role in regulating cellular differentiation [8]. Some evidence on the effective roles of oxidants or antioxidants as chemotherapeutic agents has been established $[9,10]$.

Isoliquiritigenin (ISL), a dietary flavonoid in licorice, exhibits a variety of biological activities, including antioxidant, anti-inflammatory, chemopreventive, and antitumor activities [11-14]. ISL inhibits cell proliferation and induces HeLa cell apoptosis by increasing intracellular ROS 
levels [15]. It also induces cellular differentiation and decreases ROS levels in HL-60 cells [16]. However, the role of ROS in ISL-induced cellular differentiation has not yet been fully understood.

This study aims to investigate the effects of ISL on the proliferation and differentiation of B16F0 cells. The role of ROS formation was also explored during ISL-induced differentiation in B16F0 cells. In addition, the prooxidative aspects of antioxidants were highlighted to provide theoretical basis for clinical treatment.

\section{Methods}

2.1. Reagents. Isoliquiritigenin (ISL, purity $\geq 98 \%$ ) was purchased from Jiangxi Herb Tiangong Technology Co., Ltd. (Jiangxi, China). Culture medium (RPMI 1640), 2,7-dichlorodihydro-fluorescein diacetate (DCFH-DA), dimethyl sulfoxide (DMSO), 3-(4,5-dimethylthiazol-2-yl)-2,5diphenyl tetrazolium bromide (MTT), Levodopa (L-DOPA), Phenylmethanesulfonyl fluoride (PMSF), N-acetyl-Lcysteine (NAC), and L-buthionine-(S,R) sulfoximine (BSO) were purchased from Sigma Chemical Co. (St. Louis, MO, USA). Fetal bovine serum (FBS) was purchased from Tianjin Hao Yang Biological Manufacture CO., Ltd. (Tianjin, China). Bradford protein quantitative kit and RNA extraction kit were purchased from Shanghai Sangong CO., Ltd., (Shanghai, China). First Strand cdna Synthesis Kit and cDNA amplification Kit were purchased from Formentas CO., Ltd., (Vilnius, Lithuania). Penicillin and streptomycin were obtained from Shandong Sunrise Pharmaceutical Co., Ltd. (Zibo, China). All other chemicals are of analytical grade and commercially available.

2.2. Cell Line and Cell Culture. B16F0 cells were purchased from China Center for Type Culture Collection (CCTCC, Wuhan, China). The cells were maintained in RPMI 1640 medium supplemented with $10 \%$ fetal bovine serum, and $100 \mathrm{U} / \mathrm{mL}$ penicillin, $100 \mu \mathrm{g} / \mathrm{mL}$ streptomycin at $37^{\circ} \mathrm{C}$ with $5 \% \mathrm{CO}_{2}$. The cells were split every 2 day and were diluted 1 day before each experiment.

2.3. Cell Viability Assay. Cell viability was measured using the 3-(4,5-dimethylthiazol-2-yl)-2,5-diphenyl-tetrazolium bromide (MTT) assay [17]. Cells were briefly trypsinized, seeded into 96 -well plates at $4 \times 10^{3}$ cells/well, and proincubated for $24 \mathrm{~h}$ before treatment. Thereafter, the cells were exposed to different ISL concentrations as indicated in Figure 1(a) for $24 \mathrm{~h}$ or $48 \mathrm{~h}$. The medium was after incubation, and fresh medium containing $10 \mu \mathrm{L}$ of $5 \mathrm{mg} / \mathrm{mL}$ MTT was added. The medium was removed after $4 \mathrm{~h}$ and replaced with blue formazan crystal dissolved in $100 \mu \mathrm{L}$ dimethyl sulfoxide. Absorbance at $570 \mathrm{~nm}$ was measured using a microplate reader (Thermo Varioskan Flash 3001, USA). The cell inhibition rate was calculated as $100 \% \times$ (control group A values - experimental group A values)/ control group A values.
2.4. Analysis of Morphological Changes. Morphological changes in B16F0 cells were observed under a phase contrast microscope equipped with a digital camera after $48 \mathrm{~h}$ incubation with different ISL concentrations as indicated in Figure 1(b) (Axio Observer, Zeiss, Germany). Digital images were obtained during observation under an inverted microscope at a 400x magnification. The raw accumulation of melanin by ISL treatment was recorded via transmission optical images at 200x magnification (Figure 2(a)).

2.5. Colony Formation Assay. B16F0 cells treated with or without ISL were seeded at low density (100 cells/well) in individual wells of a standard 6-well plate and grown for 10 days in Roswell Park Memorial Institute 1640 medium. Colonies were visualized by crystal violet staining and were counted. Digital images of the 6-well plate were taken, and colony formation efficiency was calculated. Colony formation efficiency $\%=$ number of colonies/number of seeded cells [18].

2.6. Melanin Content Assessment. Extracellular and intracellular melanin contents were measured according to the method described previously [19]. After incubation with ISL as indicated, concentration in Figure 1(c) for $48 \mathrm{~h}, \mathrm{~B} 16 \mathrm{~F} 0$ cells and the supernatant were collected separately. One milliliter each of $0.4 \mathrm{~mol} / \mathrm{L} 2$-[4-(2-hydroxyethyl) piperazin1-yl] ethanesulfonic acid buffer ( $\mathrm{pH} 6.8)$ and $\mathrm{EtOH}(9: 1$, $\mathrm{v} / \mathrm{v}$ ) was added to $1 \mathrm{~mL}$ medium. The optical density was measured at $405 \mathrm{~nm}$ to quantify extracellular melanin using a calibration curve obtained from synthetic melanin solution. Cells were collected by trypsinization, pelleted, washed twice with phosphate-buffered saline (PBS), and digested in $1 \mathrm{~mL}$ of $1 \mathrm{~N} \mathrm{NaOH}$ solution at $80^{\circ} \mathrm{C}$ for $1 \mathrm{~h}$ in capped tubes. The intracellular melanin was measured as described above.

2.7. Tyrosinase (TYR) Activity Assay. TYR activity was assayed by measuring the L-3,4-dihydroxyphenylalanine (LDOPA) oxidase activity using a previously described method [20]. B16F0 cells, treated by ISL as indicated concentrations and durations in Figure 2(b), were washed twice with icecold PBS, lysed with $50 \mathrm{mM}$ sodium phosphate buffer ( $\mathrm{pH}$ 6.8) containing 1\% Triton X-100 and phenylmethylsulfonyl fluoride $(0.1 \mathrm{mM})$, and frozen at $-80^{\circ} \mathrm{C}$ for $30 \mathrm{~min}$. TYR activity was then analyzed spectrophotometrically. The dopachrome concentration in the reaction mixture was measured at $475 \mathrm{~nm}$ (Thermo Varioskan Flash 3001, USA). The reaction mixture containing $140 \mu \mathrm{L}$ freshly prepared substrate solution $(0.1 \% \mathrm{~L}-\mathrm{DOPA}$ in $0.1 \mathrm{M}$ sodium phosphate, $\mathrm{pH} 6.0)$ and $70 \mu \mathrm{L}$ enzyme solution was incubated at $37^{\circ} \mathrm{C}$. The change in absorbance was measured for the first $2 \mathrm{~h}$ of the reaction (i.e., during the linear increase in absorbance). Corrections were made for the autooxidation of L-DOPA in the control. The tyrosinase (TYR) activity was normalized against the protein content of the samples, which was determined using a commercial Bradford assay kit (Sangong Co., Shanghai, China). 


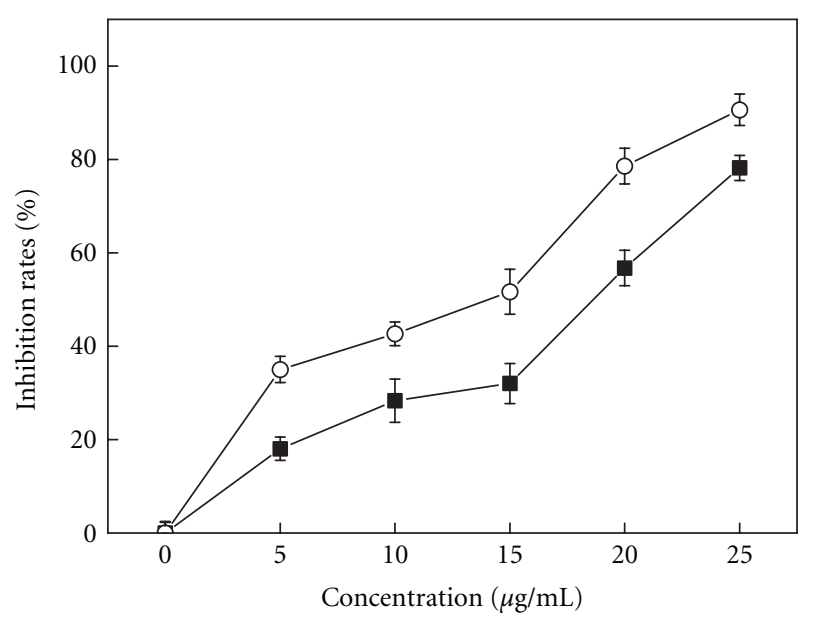

$-24 h$
$-0-48 h$

(a)

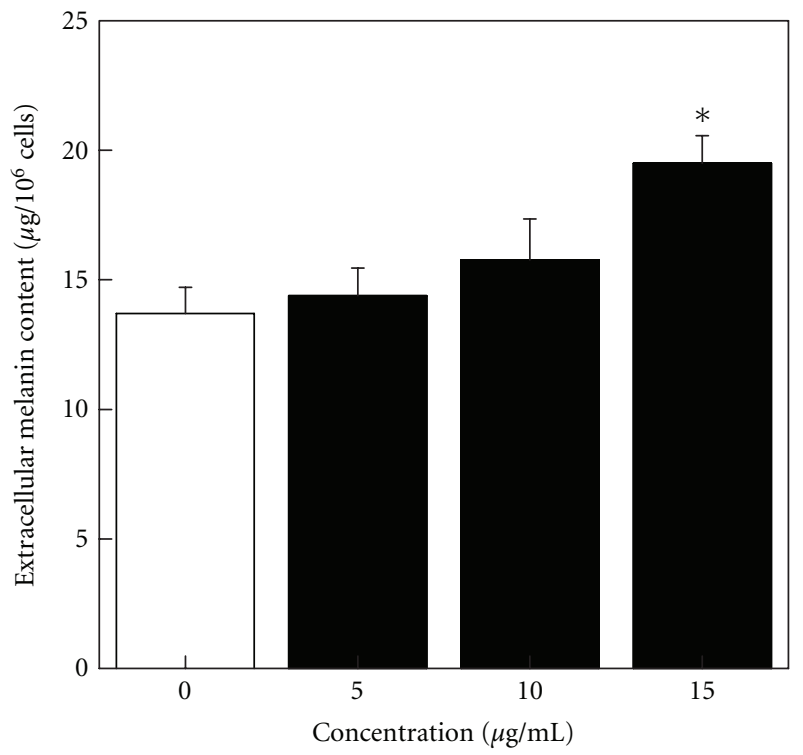

(c)
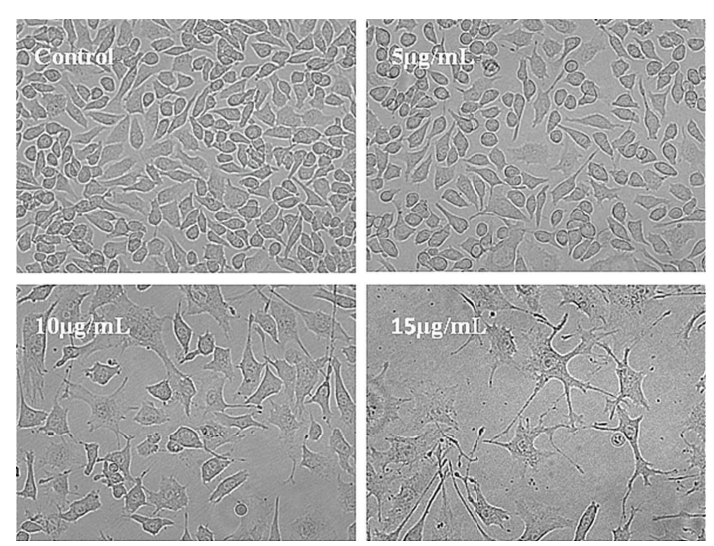

(b)

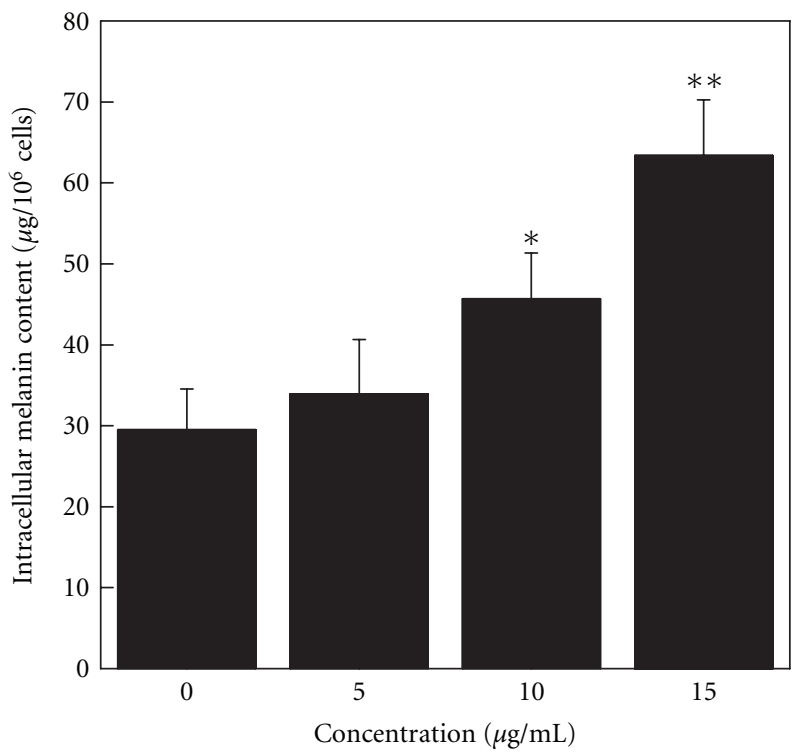

(d)

FIgURE 1: (a) Effects of ISL on proliferation of B16F0 cells. Cell inhibition rate was determined by MTT assay. Treatment of B16F0 cells by ISL $(0,5,10,15,20$, and $25 \mu \mathrm{g} / \mathrm{mL})$ for $24 \mathrm{~h}$ or $48 \mathrm{~h}$ was resulted in a significant concentration and time-dependent inhibition on cell viabilities. The data represent the means \pm SD from nine samples of three independent experiments. (b) Phase-contrast micrographs (400x) show the morphology changes of B16F0 cells treated by ISL $(0,5,10$, and $15 \mu \mathrm{g} / \mathrm{mL})$ for $48 \mathrm{~h}$. (c) The extracellular melanin contents in ISL-treated B16F0 cells for $48 \mathrm{~h} .{ }^{*} P<0.05$ versus control $(0 \mu \mathrm{g} / \mathrm{mL})$. (d) The intracellular melanin contents in ISL-treated B16F0 cells for 48 h. ${ }^{*} P<0.05,{ }^{* *} P<0.01$ versus control.

2.8. Evaluation of TYR, Trp1, and Trp2 Gene Expressions. The total cellular RNA was isolated using a commercial kit (Sangong Co., Shanghai, China). RNA quality was tested using the A260/A280 ratio and 1.5\% agarose gel electrophoresis. cDNA synthesis was performed using Moloney murine leukemia virus reverse transcriptase with a First Strand cdna Synthesis Kit (Formentas, Vilnius, Lithuania). The cDNA synthesis system was performed according to the manufacturer's instructions. The synthesized cDNA was amplified by Olig $(\mathrm{dT})_{18}$ via according to the instructions of a PCR Amplification Kit (Formentas, Vilnius, Lithuania). The
cDNA was also used for reverse transcription (RT) PCR using TYR and TYR-related proteins and TRP-1 and TRP-2, [21]. The PCR primers' (synthesized by Sangon Co.) and their cycling conditions were set as indicated (Table 1). The reaction conditions were established by $12.5 \mu \mathrm{L} 2 \times$ PCR Master (Sangong Co., Shanghai, China), $3 \mu \mathrm{L}$ cDNA template, and $0.5 \mu \mathrm{L}$ each primers. The RT-PCR products were quantified by measuring each band intensity using GelPro analysis software. The results were expressed as the ratio of the intensity of each band to the intensity of the GADPH band. 
TABle 1: Primer sequences used.

\begin{tabular}{|c|c|c|c|}
\hline Gene & Primer & Annealing temperature $/{ }^{\circ} \mathrm{C}$ & Cycles \\
\hline TYR & $\begin{array}{l}\text { (+) } 5^{\prime} \text {-GGCCAG CTT TCA GGC AGA GGT-3' } \\
(-) 5^{\prime} \text {-TGG TGC TTC ATG GGC AAA ATC-3' }\end{array}$ & 60 & 32 \\
\hline TRP-1 & $\begin{array}{l}\text { (+) } 5^{\prime} \text {-GCT GCA GGA GCC TTC TTT CTC-3' } \\
(-) 5^{\prime} \text {-AAG ACG CTG CAC TGC TGG TCT-3' }\end{array}$ & 61 & 30 \\
\hline TRP-2 & $\begin{array}{l}\text { (+) 5'-GGA TGA CCG TGA GCAATG GCC-3' } \\
(-) 5^{\prime} \text {-CGG TTG TGA CCAATG GGT GCC-3' }\end{array}$ & 63 & 30 \\
\hline GAPDH & $\begin{array}{l}\text { (+) } 5^{\prime} \text {-CAA GGT CAT CCA TGA CAA CTT-3' } \\
(-) 5^{\prime} \text {-GTC CAC CAC CCT GTT GCT GTA-3' }\end{array}$ & 58 & 28 \\
\hline
\end{tabular}
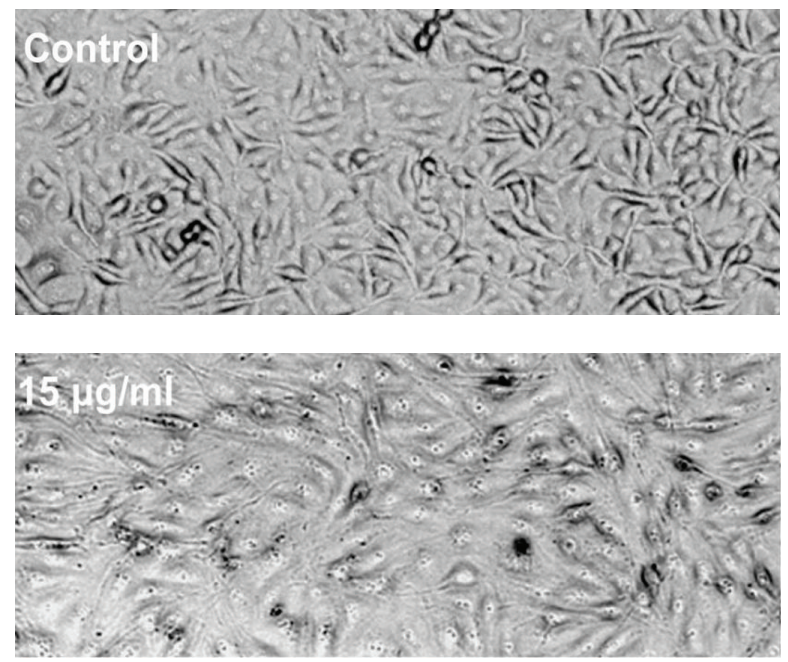

(a)

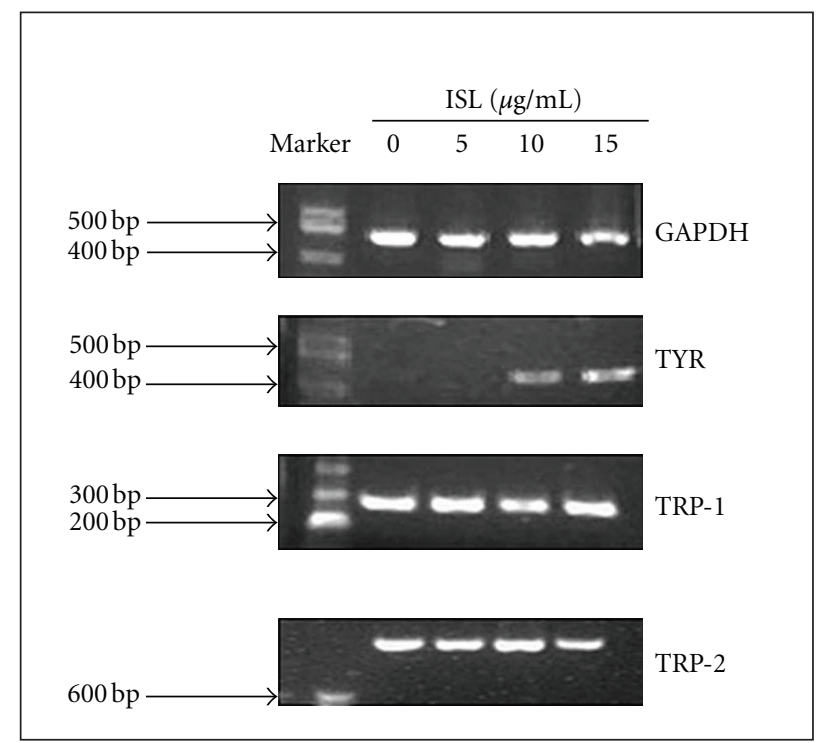

(c)

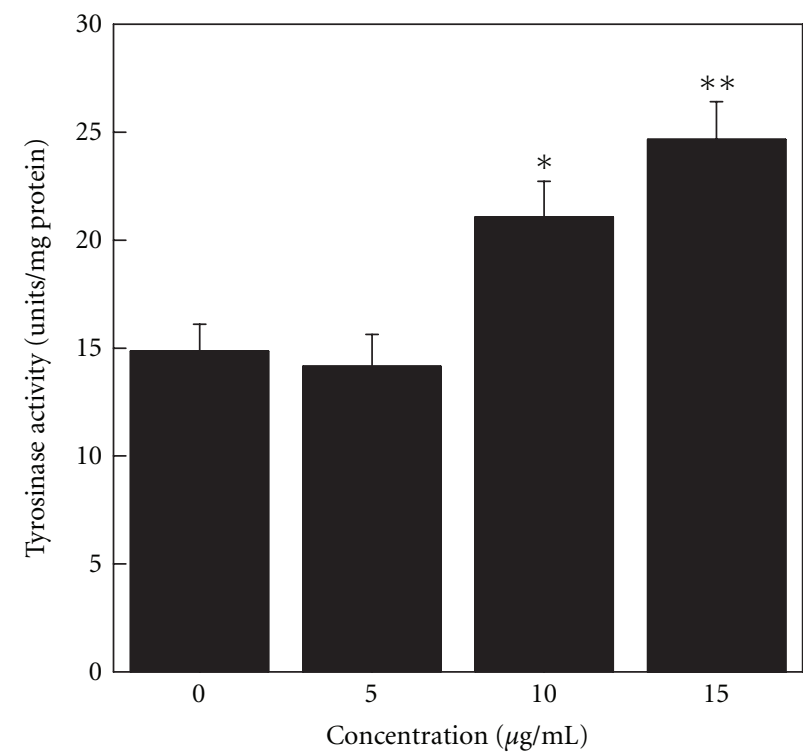

(b)
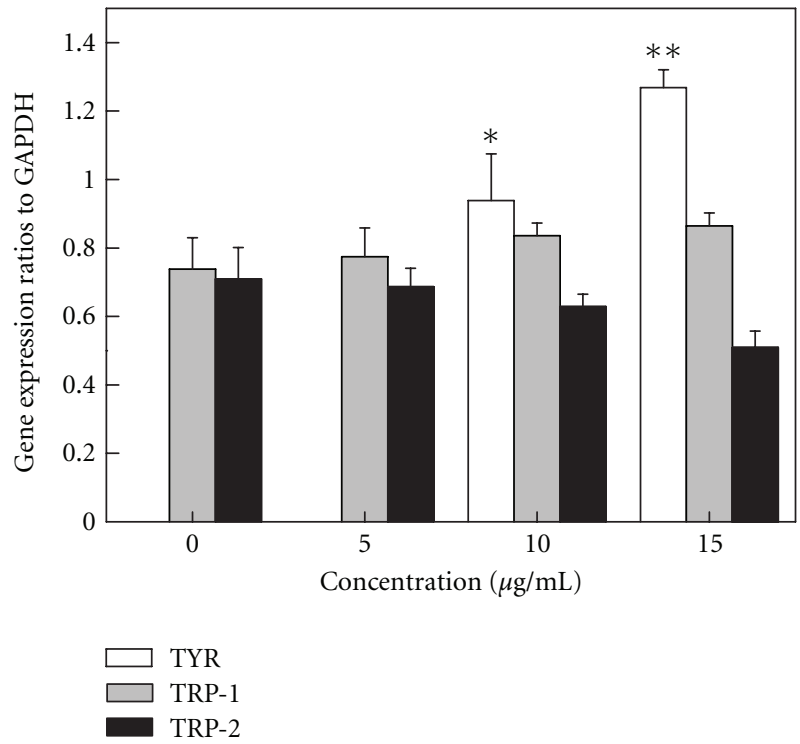

TRP-2

(d)

Figure 2: (a) Cells showed the increases of melanin after being treated by $15 \mu \mathrm{g} / \mathrm{mL}$ ISL for $48 \mathrm{~h}$ in transmission optical images (200x). (b) Effects of ISL on tyrosinase activities in B16F0 cells, ${ }^{*} P<0.05,{ }^{*} P<0.01$ versus control $(0 \mu \mathrm{g} / \mathrm{mL})$. (c) Agarose gel (1.5\%) electrophoresis of RT-PCR products showed the effects of ISL on mRNA expression of tyrosinase, TRP-1, and TRP-2 against GADPH. (d) The quantified RTPCR results in ISL treatments via relative gene expression ratios to GAPDH. Bars represent means \pm SD of three independent experiments; ${ }^{*} P<0.05,{ }^{*} P<0.01$ versus control. 
2.9. Tumorigenicity Experiments. Male C57BL/6 mice (6 weeks to 8 weeks old and weighs $18 \mathrm{~g}$ to $22 \mathrm{~g}$ ) were obtained from the Xinjiang Medical University Laboratory Animal Center (Urumqi, Xinjiang). After B16F0 melanoma cells were treated with $15 \mu \mathrm{g} / \mathrm{mL}$ ISL for $48 \mathrm{~h}, 1 \times 10^{6}$ viable B16F0 cells in $200 \mu \mathrm{L}$ culture medium were inoculated s.c. to mice. Mice were sacrificed by cervical dislocation 10 days after ISL-treated B16F0 cells were administered by injection. At the end of the experiment, mice were sacrificed according to the institutional guidelines for animal welfare. The tumors were then isolated and weighed, and images were taken. The tumor inhibition rate was calculated as follows. Tumor inhibition rate $(\%)=$ (the weight of untreated $\mathrm{B} 16 \mathrm{~F} 0$ tumors formed - the weight of ISL-treated B16F0 tumors formed)/the weight of untreated B16F0 tumors formed $\times$ $100 \%$ [22].

2.10. ROS Detection. ROS were detected as previously described [23]. Cells $\left(4 \times 10^{3}\right.$ cells/well $)$ were seeded in a 96well plate and incubated for $24 \mathrm{~h}$ at $37^{\circ} \mathrm{C}$. The appropriate drug concentrations were added in quadruplicate after incubation. The cells were then incubated further for $2 \mathrm{~h}$. 2,7-Dichlorodihydrofluorescein diacetate (DCFH-DA) was then added at a final concentration of $30 \mu \mathrm{M}$ and incubated for $40 \mathrm{~min}$. Fluorescence was read at $485 \mathrm{~nm}$ excitation and $535 \mathrm{~nm}$ emission using a fluorescence plate reader (Thermo Varioskan Flash 3001, USA). The ISL-induced ROS accumulation in cell was also recorded by using a fluorescence microscope (Axio Observer, Zeiss, Germany) at a 400x magnification. Each treatment group obtained more than 10,000 individual cells.

\section{Results}

3.1. ISL Inhibits the Proliferation of B16F0 Cells. The effects of ISL on cell proliferation were determined using MTT assay after $24 \mathrm{~h}$ or $48 \mathrm{~h}$ exposure. A significant concentration- and time-dependent reduction in cell proliferation were observed (Figure $1(\mathrm{a})$ ). The cell inhibition rate ranged from $18 \%$ to $79 \%$ and $35 \%$ to $91 \%$ after 24 and 48 h of ISL treatment (5, $10,15,20$, and $25 \mu \mathrm{g} / \mathrm{mL})$, respectively.

3.2. ISL Induces Dendrite Morphological Changes in B16FO Cells. The images in Figure 1(b) show a concentrationdependent decrease in cellular density in the ISL-treated group. Moreover, a clear morphological change was observed in ISL-treated cells. The ISL treatment induced the formation of dendrite-like projections that produced star-shaped cells compared with the rounded morphology of the untreated cells. These effects were more evident with increasing ISL concentration.

3.3. ISL Stimulates Melanin Biosynthesis. The melanin contents of the cells in each treatment were measured to investigate the depigmentation activity of ISL on B16 cells. The extracellular (Figure 1(c)) and intracellular (Figure 1(d)) melanin contents of B16F0 cells increased considerably after $15 \mu \mathrm{g} / \mathrm{mL}$ ISL stimulation. In addition, ISL-stimulated melanogenesis were concentration dependent. The extracellular melanin increased from $13.699 \mu \mathrm{g} / 10^{6}$ cells to $19.567 \mu \mathrm{g} / 10^{6}$ cells when melanoma cells were incubated for $48 \mathrm{~h}$ in ISL-containing medium. The $5 \mu \mathrm{g} / \mathrm{mL}$ and $10 \mu \mathrm{g} / \mathrm{mL}$ ISL treatments slightly increased the extracellular melanin content. However, no significant difference was found compared with that of the control (Figure 1(c)). However, the intracellular melanin content increased significantly by about twofold than that of the control after $48 \mathrm{~h}$ incubation with $15 \mu \mathrm{g} / \mathrm{mL}$ ISL (Figure $1(\mathrm{~d})$ ).

The promotion of melanin production is evident in images shown in Figure 2(a). The number of melanin pellet increased under ISL treatment. Furthermore, the morphologies of ISL-treated B16F0 cells exhibited epithelial-like structures.

3.4. ISL Increases TYR Activity. TYR activity increased significantly after $48 \mathrm{~h}$ treatment with $15 \mu \mathrm{g} / \mathrm{mL}$ ISL compared with that of the control (Figure 2(b)). The maximum enhancement in TYR activity was observed after $48 \mathrm{~h}$ treatment with $15 \mu \mathrm{g} / \mathrm{mL}$ ISL (14.1 units/mg protein in the control, 25.2 units/mg protein in the treated group, $P<$ $0.01)$.

3.5. Effects of ISL on the mRNA Expression of Melanin-Biosynthetic Genes. The mRNA levels of melanogenesis-related proteins including TYR, TRP-1, and TRP-2 in B16F0 cells were determined after ISL exposure to clarify further the TYR activation mechanism induced by ISL (Figure 2(c)). The mRNA expression of TYR increased in the $10 \mu \mathrm{g} / \mathrm{mL}(P<$ $0.05)$ and $15 \mu \mathrm{g} / \mathrm{mL}(P<0.01$, resp. $)$ ISL group as shown in Figure 2(d). However, TRP-1 and TRP-2 expressions in all the treated groups showed a slight decrease but were not significantly different $(P>0.05)$.

3.6. ISL Inhibits Colony Formation. The colony-forming efficiency of B16F0 cells was examined after $15 \mu \mathrm{g} / \mathrm{mL}$ ISL treatment. Photographs of 6-well plate from a representative experiment are shown in Figure 3(a). Untreated B16F0 cells generated a relatively higher mean number of tumor spheres when plated at a density of 100 cells/well than the $15 \mu \mathrm{g} / \mathrm{mL}$ ISL-treated group (Figure 3(b)).

The biggest or smallest colonies were revealed in photographs taken using an inverted microscope at 200x magnification (Figure 3(c)). An evident change in the colony formation of ISL-treated B16F0 cells was observed. The cells in the treated group were much smaller than the untreated B16F0 cells regardless of having the biggest or smallest colony. Furthermore, many cells could not form a colony after $15 \mu \mathrm{g} /$ mL ISL treatment.

3.7. ISL Pretreatment Reduces Tumorigenicity of B16F0 Cells In Vivo. No significant differences in tumor volumes were observed among the tumor-burdened and blank vector. The mean tumor diameters and weights in the ISL-treated group were significantly smaller than those in the blank vector 


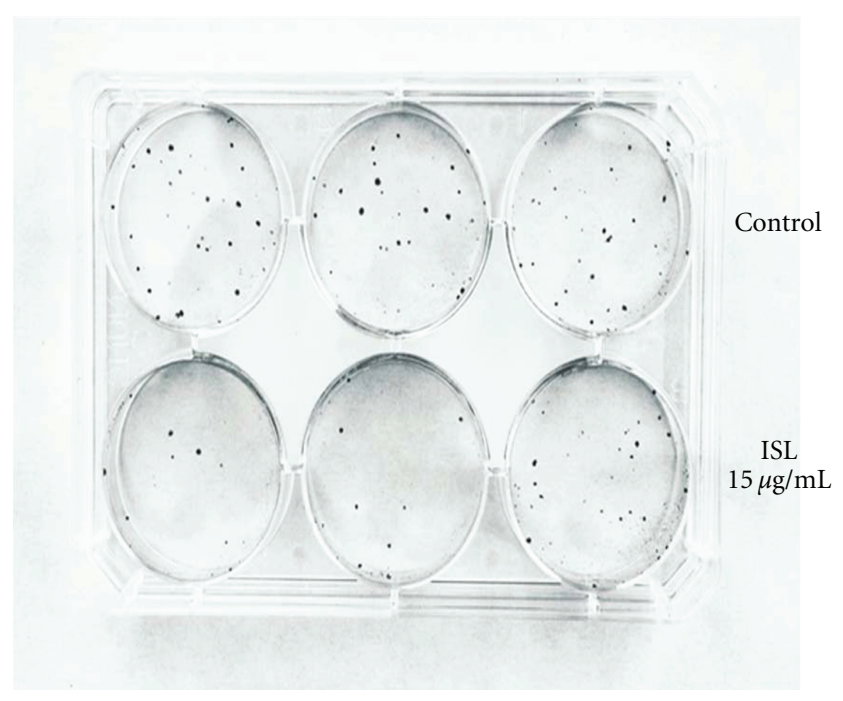

(a)
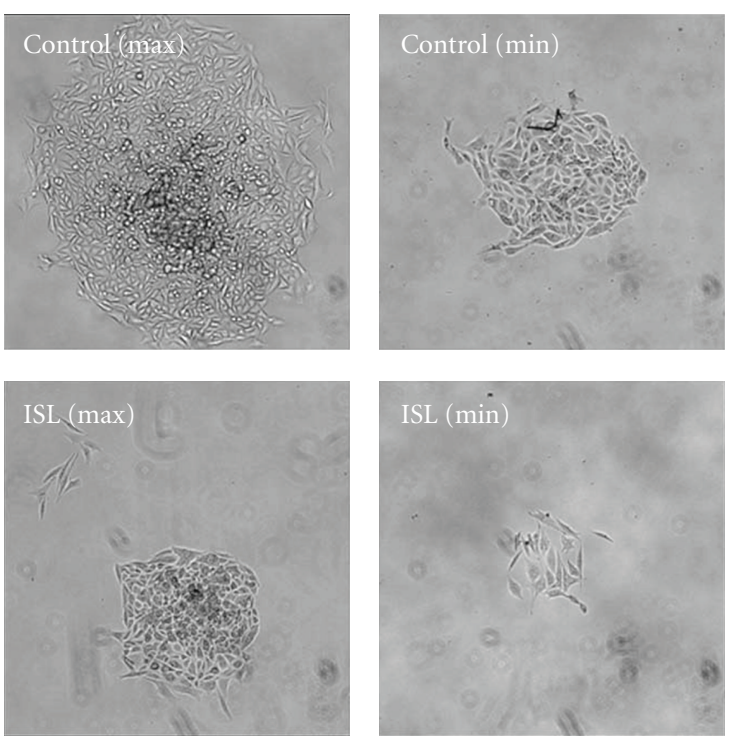

(c)

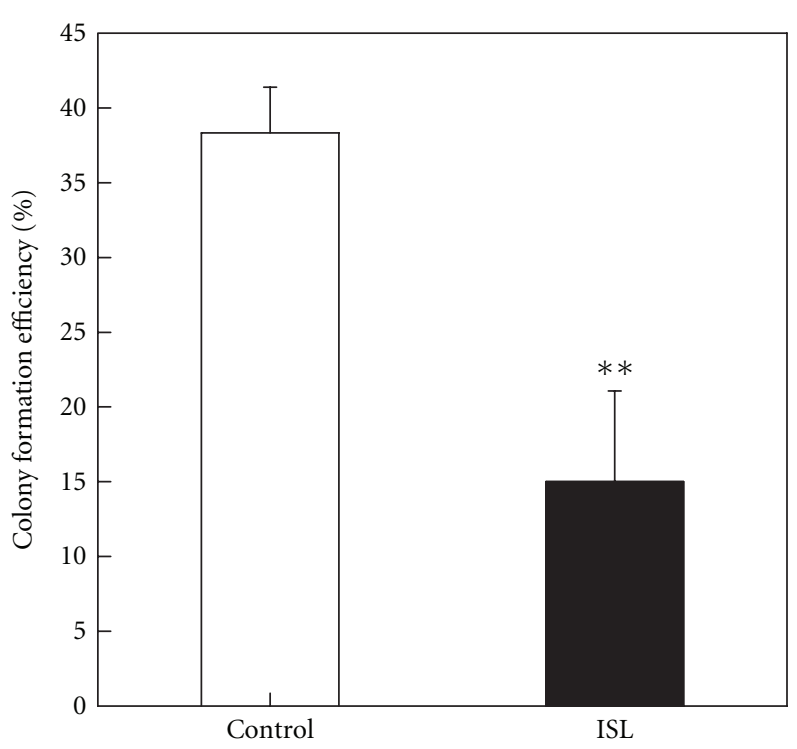

(b)

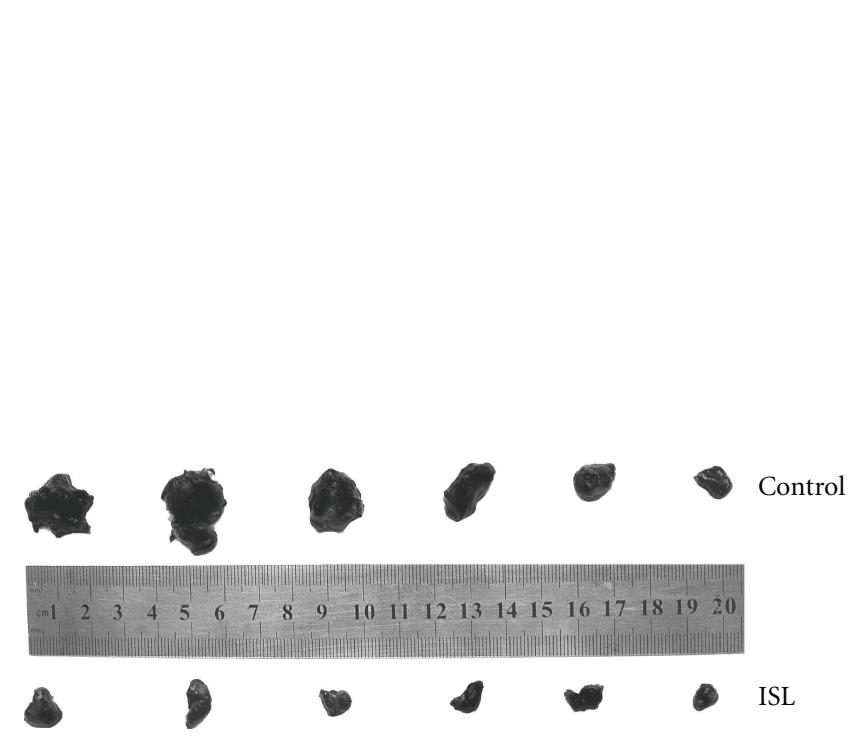

(d)

Figure 3: (a) The colony formation assay was visualized and evaluated by crystal violet-stained colonies, which showed a significant difference on colony formation between ISL treatment and control. (b) Bar graph showed the differences of colony formation between $15 \mu \mathrm{g} / \mathrm{mL}$ ISL-treated and control groups. Data were presented as mean $\pm \mathrm{SD}$ for three independent experiments, ${ }^{* *} P<0.01 \mathrm{versus}$ control $(0 \mu \mathrm{g} / \mathrm{mL})$. (c) Effects of $15 \mu \mathrm{g} / \mathrm{mL}$ ISL on the biggest (MAX) and smallest (MIN) colony formation of B16F0 cells $(\times 200)$. (d) The effect of ISL pretreatment on the formation of tumor in C57BL/6 mice. B16F0 melanoma cells were treated with $15 \mu \mathrm{g} / \mathrm{mL}$ ISL for $48 \mathrm{~h}$ prior to s.c. administration. The diameter and size of tumor were also calculated to represent the inhibition of tumor by ISL.

group $(P<0.01)$. The tumor inhibition rate of the ISLtreated group was $29.6 \%$ compared with the blank vector group (Figure 3(d)).

3.8. ISL Increases Intracellular ROS Formation. The fluorescent probe DCFH-DA was used to measure the effects of ISL on the intracellular ROS levels in B16F0 cells. ISL treatment significantly increased intracellular ROS levels in B16F0 cells in a concentration-dependent manner, as shown in Figure 4(a). A significant difference was observed between both the $10 \mu \mathrm{g} / \mathrm{mL}(P<0.05)$ and $15 \mu \mathrm{g} / \mathrm{mL}(P<0.01)$ ISL-treated groups and the control group. The $15 \mu \mathrm{g} / \mathrm{mL}$ ISL-treated group increased about twofold than that of the control group. Fluorescence intensity after incubation with ISL $(15 \mu \mathrm{g} / \mathrm{mL}$ for $48 \mathrm{~h})$ was remarkably higher compared with the basal level in the untreated control group (Figure 4(a)). DCFH-DA staining clearly illustrated the presence of identical cell populations in all cases. Thus, the ISL-mediated promotion of fluorescence intensity was evident. 

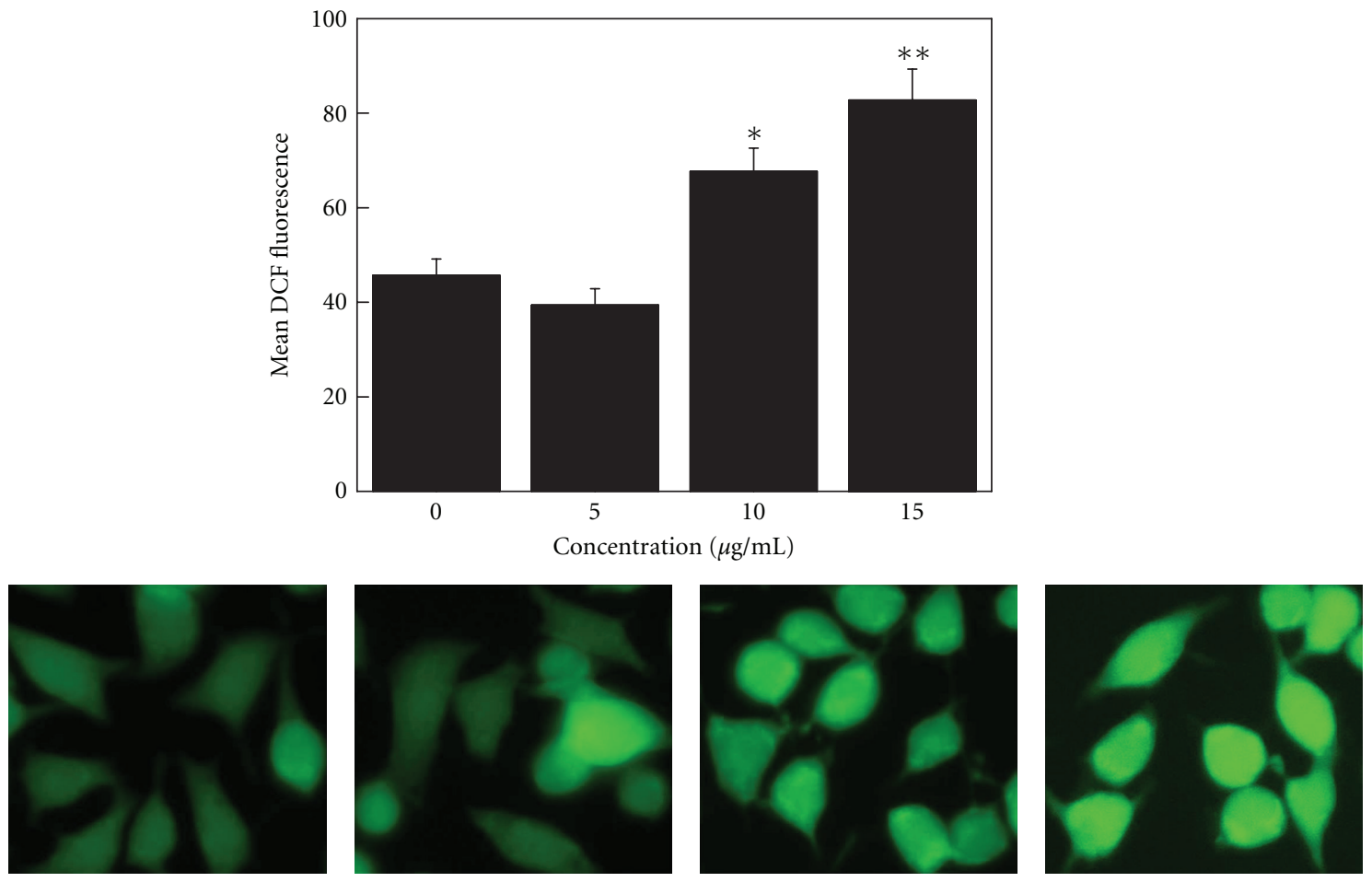

(a)
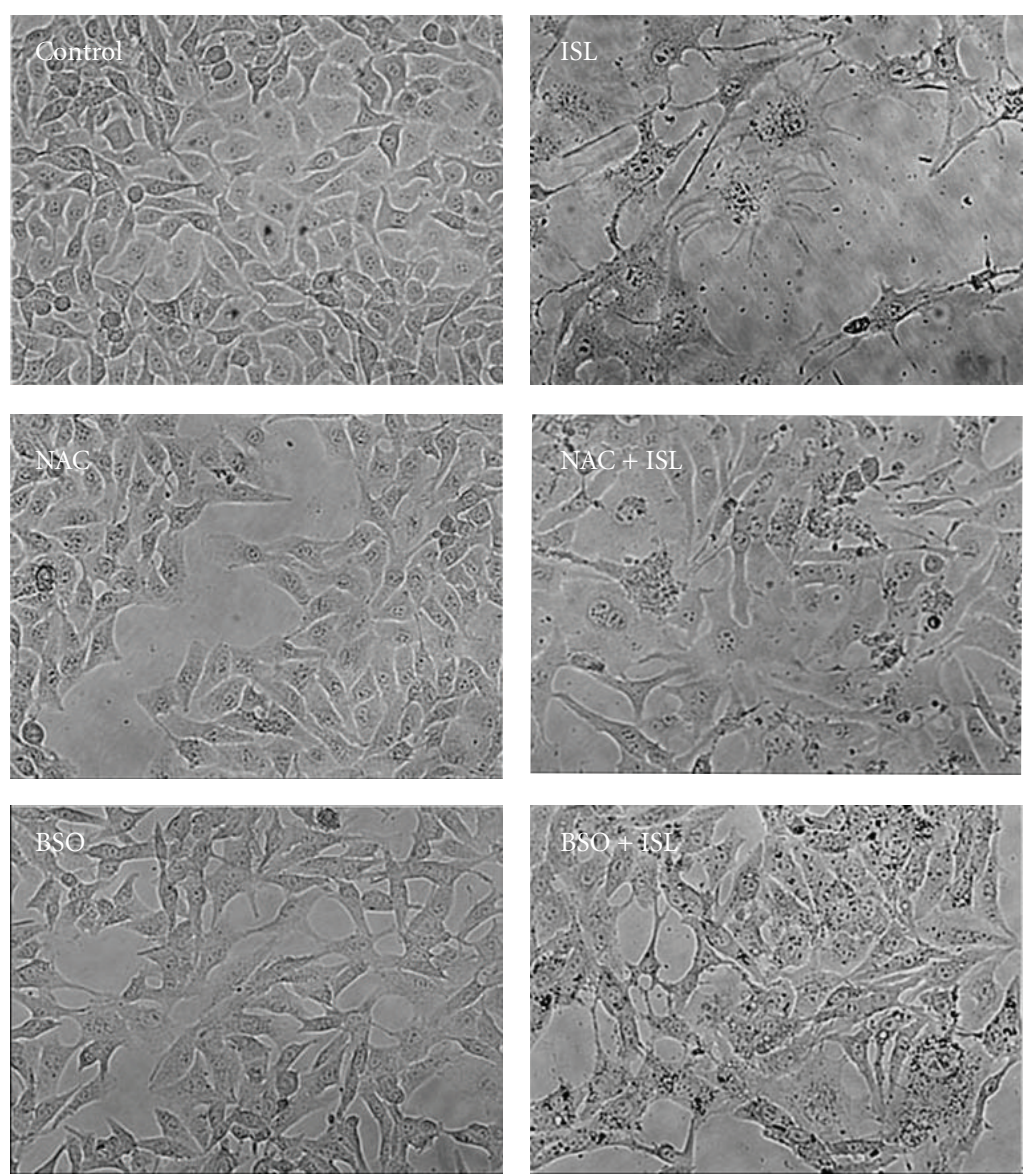

Morphology changes of B16F0 cells in treatments by ISL plus redox modulators

(b)

Figure 4: Continued. 


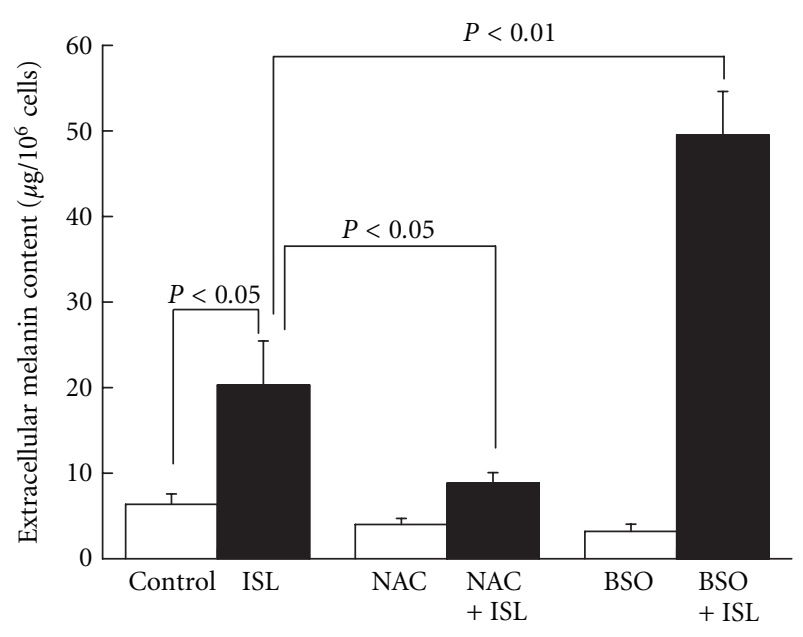

(c)

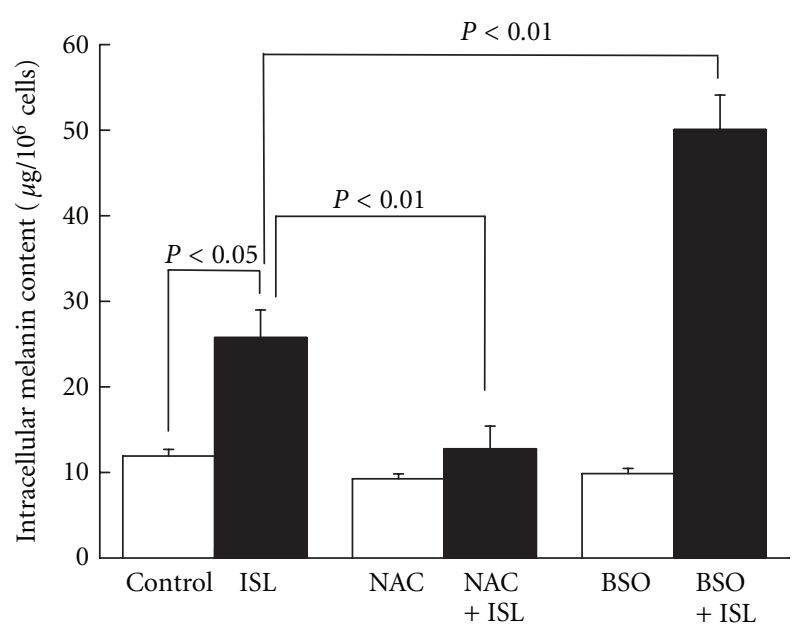

(d)

FIGURE 4: (a) Effects of ISL on intracellular ROS level in B16F0 cells data represent three separate experiments, ${ }^{*} P<0.05$, and ${ }^{* *} P<0.01$ compared with control group $(0 \mu \mathrm{g} / \mathrm{mL})$. Photo of DCF fluorescence in cell was also taken at a $400 \mathrm{x}$ magnification parallel to ISL-treatment. (b) Phase-contrast micrographs of B16F0 cells showed the morphology changes and melanin pellet $(\times 400)$ after treated by $15 \mu \mathrm{g} / \mathrm{mL}$ ISL alone or combined with $200 \mu \mathrm{M} \mathrm{NAC/BSO}$ pretreatment. (c) Effects of $200 \mu \mathrm{M} \mathrm{NAC/BSO}$ pretreatment with or without $15 \mu \mathrm{g} / \mathrm{mL}$ ISL treatment on extracellular melanin levels in B16F0 cells. (d) Effects of $200 \mu \mathrm{M}$ NAC/BSO pretreatment with or without $15 \mu \mathrm{g} / \mathrm{mL}$ ISL treatment on intracellular melanin levels in B16F0 cells.

3.9. Role of ROS in the ISL-Induced Dendrite Morphological Changes of B16FO Cells. Given that increasing intracellular ROS level was related to ISL-induced cellular differentiation, cellular redox state modulators were added to determine the interferential effects of ROS against ISL-induced differentiation. ROS production was inhibited with a pretreated antioxidant $\mathrm{N}$-acetyl-cysteine (NAC, $200 \mu \mathrm{M}$ ), a precursor of cysteine, and was promoted with a pretreated prooxidant L-buthionine-(S,R) sulfoximine (BSO, $200 \mu \mathrm{M}$ ), a glutathione (GSH) synthesis enzymatic inhibitor. All these redox modulators' pretreatments were taken for $2 \mathrm{~h}$ prior to ISL treatments, which is acceptable for both reagent cause no significant effect on basal levels of cell growth.

Two redox status modulators were employed to detect the effects of ROS formation on ISL-induced morphological changes and to understand the role of ROS in ISL-induced cellular differentiation. Notably, no significant effects on the morphology were observed in B16F0 cells under treatment with NAC and BSO alone. However, ISL-induced dendrite morphological changes were alleviated with the pretreatment of NAC but were enhanced by pretreatment with BSO. An increase in the melanin pellet could also be observed (Figure 4(b)).

\subsection{Effects of ROS on Melanin Production in ISL-Treated} B16F0 Cells. ROS formation may be related to extracellular melanin secretion and intracellular melanin synthesis. The effects of NAC or BSO on melanin production during the ISL-induced cellular differentiation of B16F0 cells were investigated to verify this possibility. The results presented in Figures 4(c) and 4(d) show that extracellular and intracellular melanin levels under ISL treatment were upregulated with the pretreatment of BSO but depleted with the pretreatment of NAC.

3.11. Effects of ROS on the mRNA Expression of Melanin Biosynthetic Genes in ISL-Treated B16FO Cells. NAC or BSO was used to accommodate the redox state to clarify the effects of ROS formation on melanin biosynthetic gene expression in ISL-treated B16F0 cells. The effects of NAC or BSO treatment alone on TYR, TRP-1, and TRP-2 mRNA content showed no significant differences compared with the control (data not shown). However, the expression of TYR mRNA was decreased in NAC pretreated plus ISL-treated groups but increased in BSO pretreated- plus ISL treated-groups compared with that of the ISL-treated only group $\left({ }^{*} P<0.05\right)$. TRP-1 mRNA expression was upregulated by pretreatment with NAC or BSO $(* P<0.05)$, whereas TRP-2 mRNA expression decreased slightly in the BSO pretreated- and ISL-treated groups. However, no significant difference was observed $(P>0.05)$ (Figures 5(a) and 5(b)).

\section{Discussion}

Continuous division and constant multiplication are essential characteristics of a malignant tumor. Therefore, the inhibitory effects of multiplication and tumorigenicities in vitro or in vivo are a significant appraisal of induced differentiation. Morphological changes with dendrite outgrowth and melanogenesis are considered specific differentiation markers for B16F0 cells [24]. TYR activity and melanin content are well-known molecular markers of melanoma cellular differentiation $[25,26]$. TYR is very important in controlling melanogenesis. Melanin content is correlated with TYR activity but not with the protein level [27]. 


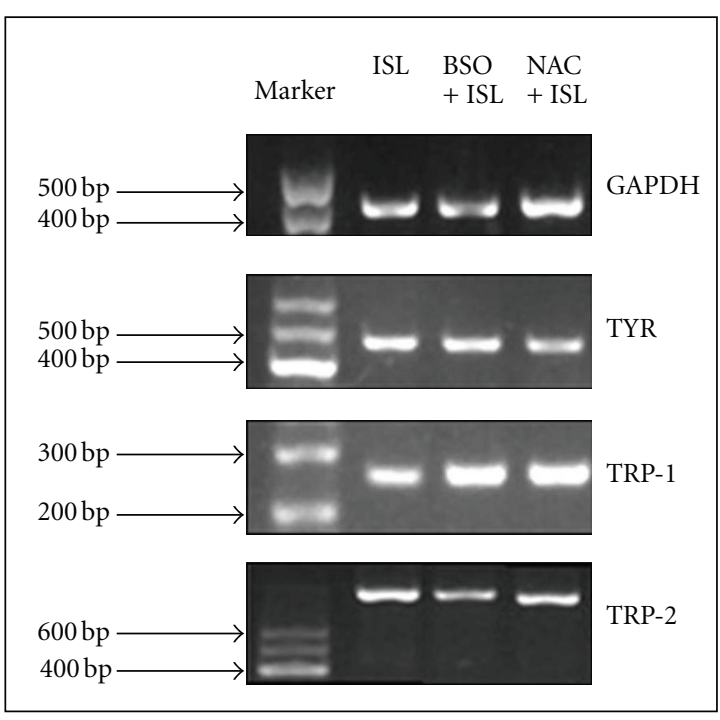

(a)

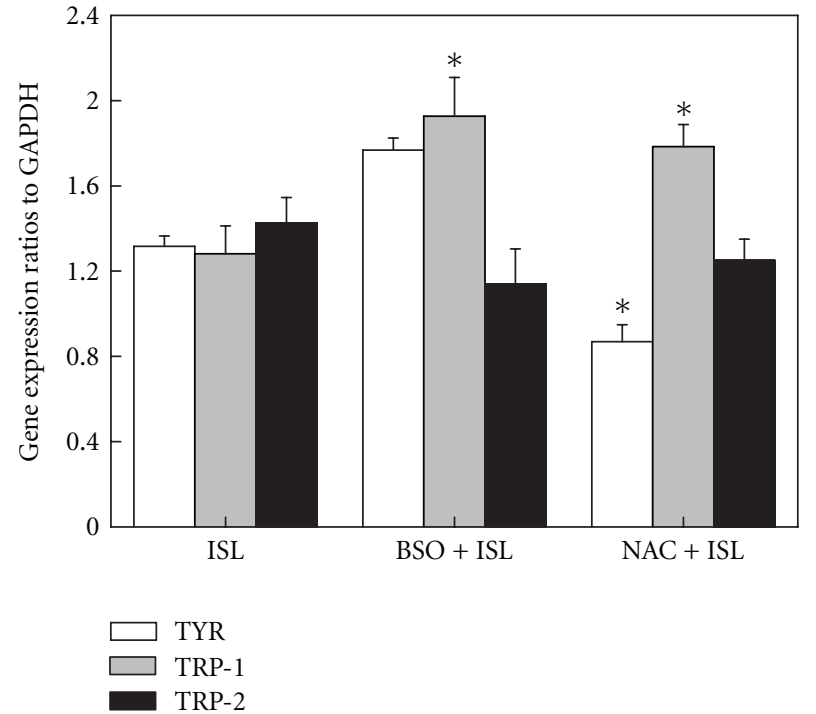

(b)

Figure 5: (a) Agarose gel (1.5\%) electrophoresis of RT-PCR products showed the effects of $15 \mu \mathrm{g} / \mathrm{mL}$ ISL alone and associates with $200 \mu \mathrm{M}$ NAC/BSO pretreatment on the mRNA expression of TYR, TRP-1, and TRP-2 against GADPH. (b) The quantified RT-PCR results in ISL treatments via relative gene expression ratios to GAPDH. Bars represent means \pm SD of three independent experiments $* P<0.05$, $* * P<$ 0.01 versus ISL-treatment group.

ISL significantly inhibited the proliferation of the B16F0 cell line. A clear morphological change was observed after ISL treatment, which induced the formation of dendritic projections that gave the cells a star-like shape compared with the rounded morphology of untreated cells. ISL treatment increased melanin production and upregulated TYR activity and mRNA expression. ISL significantly decreased the size and number of colonies formed in vitro, as well as the tumorigenicity of cells in vivo. All results show a decreased malignant characteristics of B16F0 cells with ISL treatment and an increased cell normalization-related properties. All these changes suggest that the B16F0 cells tended towards normalization and confirm that ISL induces redifferentiation and stimulates reversion against the malignant phenotype in B16F0 cells.

The intracellular ROS levels in B16F0 cells were significantly increased after ISL exposure. The modulation of intracellular ROS levels by BSO and NAC promoted and inhibited B16F0 cellular differentiation, respectively. BSO promotes high ROS levels by depleting reduced GSH [28]. NAC, however, elevates GSH levels, scavenges intracellular ROS, and protects against the initiation of apoptosis [29]. Further experiments showed that ISL combined with NAC decreased ROS and inhibited cellular differentiation, whereas ISL combined with BSO increased ROS and promoted cellular differentiation. ISL treatment not only induced ROS generation, but also verified the close relationship between ROS level and ISL-induced cellular differentiation.

ROS function as signaling molecules to mediate various biological responses, including cell growth and gene expression [30], and play important roles in the regulation of melanocyte proliferation and melanogenesis. ROS scavengers may downregulate melanogenesis [31]. Melanoma, like many other cancer subtypes, exhibits reversible defects in cellular differentiation [32]. Furthermore, the redox status plays an important role in regulating cellular differentiation. The inhibition of NADPH oxidase activity promotes B16 melanoma cellular differentiation. Cellular ROS production and NADPH oxidase in cells are closely correlated. NADPH oxidase is the major source of ROS induction in the membrane channel. Malignant cells are often under self-inflicted (and/or host-inflicted) oxidative stress, thus, contributing to the malignancy [7]. ISL was found to increase intracellular ROS of B16F0 cells significantly and trigger cellular differentiation. One possible tumor treatment approach would be to stress these cells further by providing ROS-generating agents. This step should limit the effects of ROS on normal cells and provided ROS levels do not rise too high. However, such circumstances will occur nevertheless, given an already elevated ROS generation, which pushes malignant cells to the point at which the cells can no longer cope with increasing oxidative damage.

Oxidative stress has been implicated in cancer development. The overexpression of oxidant enzymes reduces tumorigenesis in several human cancer cell lines and carcinogenesis in mouse models. Many (possibly all) antitumor agents may cause oxidative stress by increasing ROS formation, which enhances their anticancer effects [33]. On the other hand, interfering with the ROS-antioxidant balance in cancers has risks. For example, arsenic trioxide $\left(\mathrm{As}_{2} \mathrm{O}_{3}\right)$ may act against acute promyelocytic leukemia by causing oxidative stress [34], but $\mathrm{As}_{2} \mathrm{O}_{3}$ can also be carcinogenic, and ROS is most likely to be involved in the cancer development mechanism. Direct damage to DNA is believed to be a key, albeit insufficient, event that triggers cancer, suggesting that the ability of ROS to suppress apoptosis and promote 
proliferation, invasiveness, and metastasis (and, possibly, angiogenesis) is also important. Some reports have shown the important role of redox homeostasis in cellular differentiation. An alteration in the redox homeostasis of cells implies a change in ROS generation or metabolism.

Our data show that ISL-induced differentiation of B16F0 cells accompanied increased ROS formation. Further studies exploring the mechanisms involved in ISL-induced differentiation are necessary, specifically that exploring the relationship between ISL-induced differentiation and intracellular ROS formation, as well as the expression of critical molecules involved in intracellular ROS-mediated cancer differentiation.

\section{Abbreviations}

BSO: $\quad$ D,L-buthionine-(S,R)sulfoximide

DCFH-DA: 2,7-Dichlorodihydrofluoresceindiacetate

GAPDH: Glyceraldehyde-3-phosphatedehydrogenase

ISL: Isoliquiritigenin

MTT: $\quad$ Methylthiazolyltetrazolium

NAC: $\quad$ N-acetyl-L-cysteine

ROS: Reactiveoxygenspecies

TYR: Tyrosinase.

\section{Authors' Contribution}

X. Chen and B. Zhang are contributed equally to this work.

\section{Acknowledgments}

This study was supported by the National Natural Science Foundation of China (no. 30960451), the Major State Basic Research Development Program (2010CB535003), the Outstanding Youth Research Program of Xinjiang Production and Construction Corps (2011CD006), International Scientific and Technological Cooperation Projects (2012BC001), and Grand Fundamental Research Program of Shihezi University (ZRKX2009ZD01).

\section{References}

[1] M. T. Hoeng and L. F. Eichenfield, "The rising incidence of melanoma in children and adolescents," Dermatology Nursing, vol. 12, pp. 188-193, 2000.

[2] W. Englaro, R. Rezzonico, M. Durand-Clement, D. Lallemand, J. P. Ortonne -, and R. Ballotti, "Mitogen-activated protein kinase pathway and AP-1 are activated during cAMP-induced melanogenesis in B-16 melanoma cells," The Journal of Biological Chemistry, vol. 270, no. 41, pp. 24315-24320, 1995.

[3] R. Buscà, C. Bertolotto, J. P. Ortonne, and R. Ballotti, "Inhibition of the phosphatidylinositol 3-kinase/p70(S6)-kinase pathway induces B16 melanoma cell differentiation," The Journal of Biological Chemistry, vol. 271, no. 50, pp. 3182431830, 1996.

[4] W. Englaro, C. Bertolotto, R. Buscà et al., "Inhibition of the mitogen-activated protein kinase pathway triggers B16 melanoma cell differentiation," The Journal of Biological Chemistry, vol. 273, no. 16, pp. 9966-9970, 1998.
[5] X. Zhao, Y. Wakamatsu, M. Shibahara et al., "Mannosylerythritol lipid is a potent inducer of apoptosis and differentiation of mouse melanoma cells in culture," Cancer Research, vol. 59, no. 2, pp. 482-486, 1999.

[6] M. B. Sporn and A. B. Roberts, "Role of retinoids in differentiation and carcinogenesis," Cancer Research, vol. 43, no. 7, pp. 3034-3040, 1983.

[7] Y. Zhao, J. Liu, and K. E. McMartin, "Inhibition of NADPH oxidase activity promotes differentiation of B16 melanoma cells," Oncology Reports, vol. 19, no. 5, pp. 1225-1230, 2008.

[8] J. Smith, E. Ladi, M. Mayer-Pröschel, and M. Noble, "Redox state is a central modulator of the balance between selfrenewal and differentiation in a dividing glial precursor cell," Proceedings of the National Academy of Sciences of the United States of America, vol. 97, no. 18, pp. 10032-10037, 2000.

[9] D. K. S. Clair, T. D. Oberley, K. E. Muse, and W. H. S. Clair, "Expression of manganese superoxide dismutase promotes cellular differentiation," Free Radical Biology and Medicine, vol. 16, no. 2, pp. 275-282, 1994.

[10] J. M. C. Gutteridge and B. Halliwell, "Free radicals and antioxidants in the year 2000. A historical look to the future," Annals of the New York Academy of Sciences, vol. 899, pp. 136147, 2000.

[11] Y. M. Kim, T. H. Kim, Y. W. Kim et al., "Inhibition of liver $\mathrm{X}$ receptor- $\alpha$-dependent hepatic steatosis by isoliquiritigenin, a licorice antioxidant flavonoid, as mediated by JNK1 inhibition," Free Radical Biology and Medicine, vol. 49, no. 11, pp. 1722-1734, 2010.

[12] V. R. Yadav, S. Prasad, B. Sung, and B. B. Aggarwal, "The role of chalcones in suppression of NF- $\kappa \mathrm{B}$-mediated inflammation and cancer," International Immunopharmacology, vol. 11, no. 3, pp. 295-309, 2011.

[13] S. Shibata, "A drug over the millennia: pharmacognosy, chemistry, and pharmacology of licorice," Yakugaku Zasshi, vol. 120, no. 10, pp. 849-862, 2000.

[14] A. D. Kinghorn, B. N. Su, S. J. Dae et al., "Natural inhibitors of carcinogenesis," Planta Medica, vol. 70, no. 8, pp. 691-705, 2004.

[15] X. Yuan, B. Zhang, N. Chen et al., "Isoliquiritigenin treatment induces apoptosis by increasing intracellular ROS levels in HeLa cells," Journal of Asian Natural Products Research, vol. 14, no. 8, pp. 789-798, 2012.

[16] D. Li, Z. Wang, H. Chen et al., "Isoliquiritigenin induces monocytic differentiation of HL-60 cells," Free Radical Biology and Medicine, vol. 46, no. 6, pp. 731-736, 2009.

[17] T. Mosmann, "Rapid colorimetric assay for cellular growth and survival: application to proliferation and cytotoxicity assays," Journal of Immunological Methods, vol. 65, no. 1-2, pp. 55-63, 1983.

[18] Y. Liang, X. Hou, Q. Cui et al., “Skp2 expression unfavorably impacts survival in resectable esophageal squamous cell carcinoma," Journal of Translational Medicine, vol. 18, pp. 1073, 2012.

[19] D. Alesiani, R. Cicconi, M. Mattei, C. Montesano, R. Bei, and A. Canini, "Cell cycle arrest and differentiation induction by 5,7-dimethoxycoumarin in melanoma cell lines," International Journal of Oncology, vol. 32, no. 2, pp. 425-434, 2008.

[20] M. Y. Choi, H. S. Song, H. S. Hur, and S. S. Sim, "Whitening activity of luteolin related to the inhibition of cAMP pathway in $\alpha$-MSH-stimulated B16 melanoma cells," Archives of Pharmacal Research, vol. 31, no. 9, pp. 1166-1171, 2008.

[21] Y. M. Choi, H. J. Jun, K. Dawson et al., "Effects of the isoflavone puerarin and its glycosides on melanogenesis in B16 
melanocytes," European Food Research and Technology, vol. 231, no. 1, pp. 75-83, 2010.

[22] Y. L. Pan, S. Zheng, Z. X. Xiao, J. Cao, and H. P. Yao, "Subcutaneous transplantation of microencapsulated Chinese hamster ovary $(\mathrm{CHO})$ cells/pcDNA 3.1/mIL-12 and subcutaneous transplantation of microencapsulated $\mathrm{CHO} / \mathrm{pcDNA} 3.1 / \mathrm{mIL}$ 12 combined with 5-fluoro-uracil in treatment of tumorburdened mice," Zhonghua yi xue za zhi, vol. 83, no. 1, pp. 51-54, 2003.

[23] V. G. Martinez, K. J. Williams, I. J. Stratford, M. Clynes, and R. O'Connor, "Overexpression of cytochrome P450 NADPH reductase sensitises MDA 231 breast carcinoma cells to 5fluorouracil: Possible mechanisms involved," Toxicology in Vitro, vol. 22, no. 3, pp. 582-588, 2008.

[24] R. M. Umek, A. D. Friedman, and S. L. McKnight, "CCAATenhancer binding protein: a component of a differentiation switch," Science, vol. 251, no. 4991, pp. 288-292, 1991.

[25] P. Valverde, J. C. Garcia-Borron, C. Jimenez-Cervantes, F. Solano, and J. A. Lozano, "Tyrosinase isoenzymes in mammalian melanocytes. 2. Differential activation by $\alpha$-melanocyte-stimulating hormone," European Journal of Biochemistry, vol. 217, no. 2, pp. 541-548, 1993.

[26] A. Gismondi, A. Lentini, C. Tabolacci, B. Provenzano, and S. Beninati, "Transglutaminase-dependent antiproliferative and differentiative properties of nimesulide on B16-F10 mouse melanoma cells," Amino Acids, vol. 38, no. 1, pp. 257-262, 2010.

[27] K. Iozumi, G. E. Hoganson, R. Pennella, M. A. Everett, and B. B. Fuller, "Role of tyrosinase as the determinant of pigmentation in cultured human melanocytes," Journal of Investigative Dermatology, vol. 100, no. 6, pp. 806-811, 1993.

[28] D. W. Hedley, E. A. McCulloch, M. D. Minden, S. Chow, and J. Curtis, "Antileukemic action of buthionine sulfoximine: evidence for an intrinsic death mechanism based on oxidative stress," Leukemia, vol. 12, no. 10, pp. 1545-1552, 1998.

[29] M. Zafarullah, W. Q. Li, J. Sylvester, and M. Ahmad, "Molecular mechanisms of N-acetylcysteine actions," Cellular and Molecular Life Sciences, vol. 60, no. 1, pp. 6-20, 2003.

[30] K. Bedard and K. H. Krause, "The NOX family of ROSgenerating NADPH oxidases: physiology and pathophysiology," Physiological Reviews, vol. 87, no. 1, pp. 245-313, 2007.

[31] Y. J. Kim, "Antimelanogenic and antioxidant properties of gallic acid," Biological and Pharmaceutical Bulletin, vol. 30, no. 6, pp. 1052-1055, 2007.

[32] M. Leszczyniecka, T. Roberts, P. Dent, S. Grant, and P. B. Fisher, "Differentiation therapy of human cancer: basic science and clinical applications," Pharmacology and Therapeutics, vol. 90, no. 2-3, pp. 105-156, 2001.

[33] J. Pan and S. C. J. Yeung, "Recent advances in understanding the antineoplastic mechanisms of farnesyltransferase inhibitors," Cancer Research, vol. 65, no. 20, pp. 9109-9112, 2005.

[34] W. C. Chou, C. Jie, A. A. Kenedy, R. J. Jones, M. A. Trush, and C. V. Dang, "Role of NADPH oxidase in arsenic-induced reactive oxygen species formation and cytotoxicity in myeloid leukemia cells," Proceedings of the National Academy of Sciences of the United States of America, vol. 101, no. 13, pp. 4578-4583, 2004. 


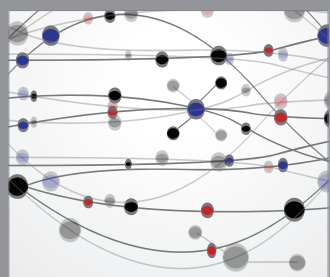

The Scientific World Journal
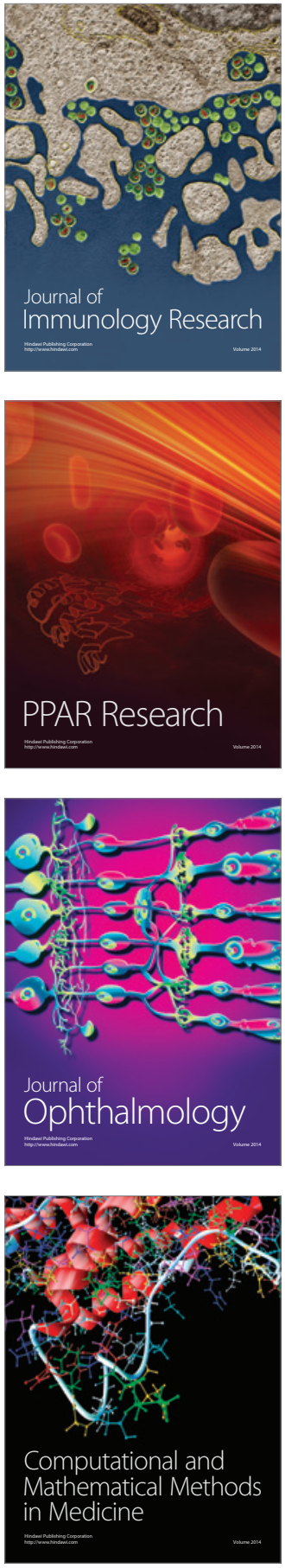

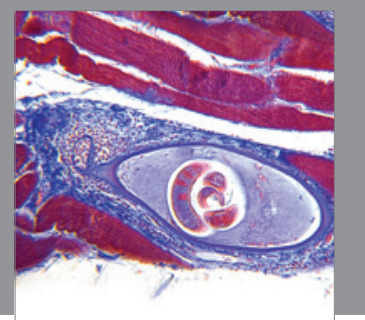

Gastroenterology

Research and Practice
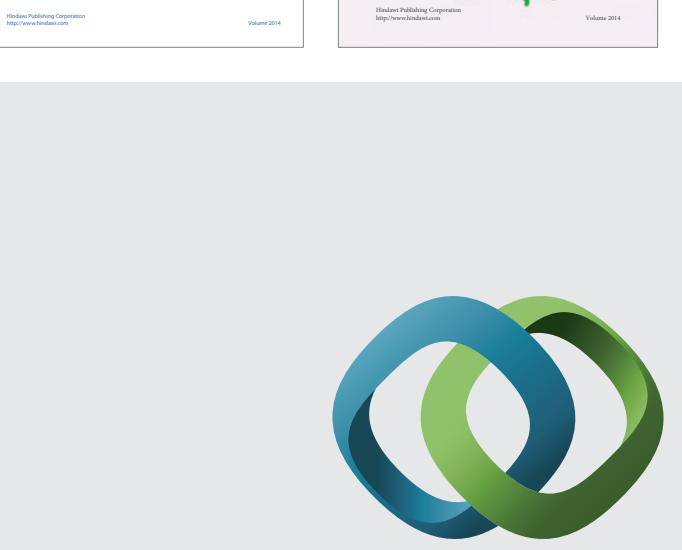

\section{Hindawi}

Submit your manuscripts at

http://www.hindawi.com
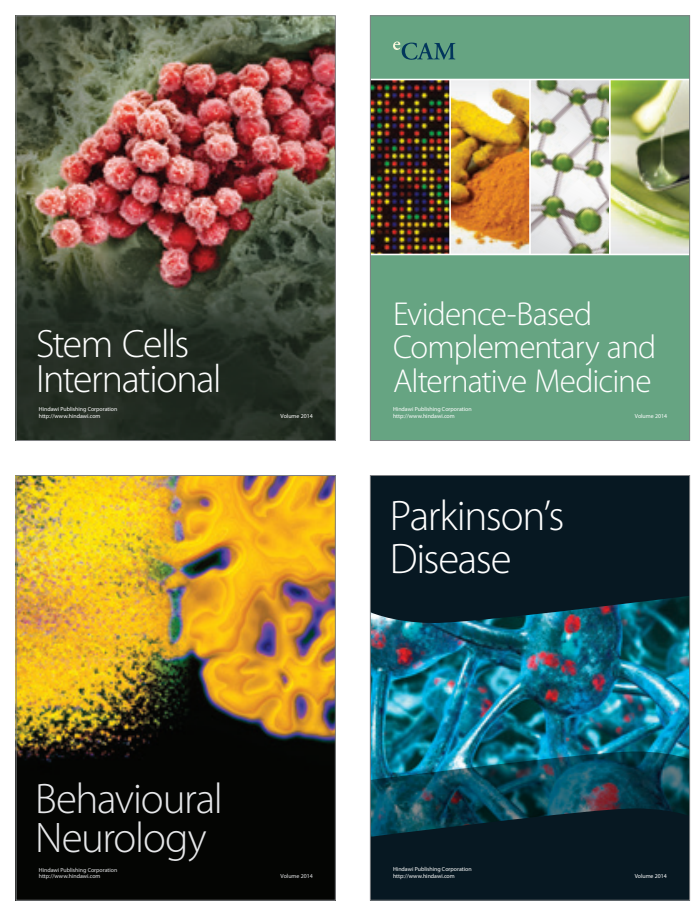

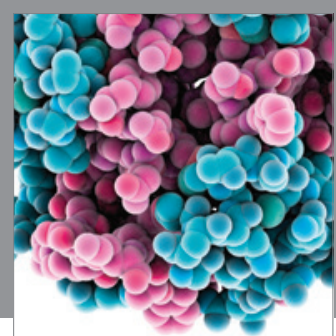

Journal of
Diabetes Research

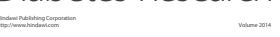

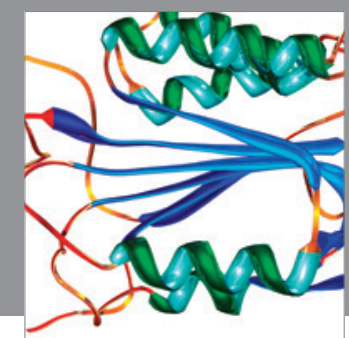

Disease Markers
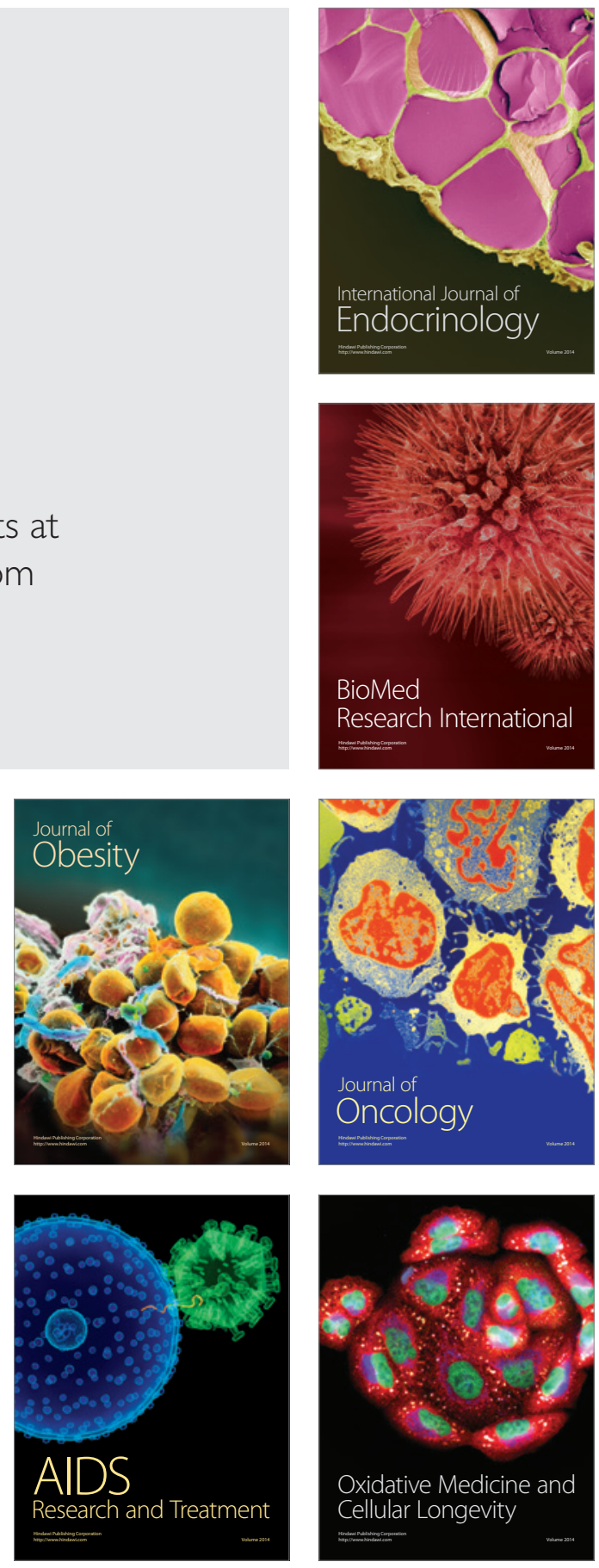